\title{
OVERSTAY TEACHER TRANSFERS IN PUBLIC SCHOOLS IN SRI LANKA: IMPACT ON SCHOOL MANAGEMENT AND PERFORMANCE
}

\author{
Ameesha Ramithanjalee Wijayatunga \\ School of Education, University of Leicester, UK
}

\begin{abstract}
In many developing countries, there is no clear policy on teacher transfers in the public sector. The transfers tend to be ad-hoc and based on personal interests, political interferences and other indirect factors with no regard to improving quality of education. In Sri Lanka teachers in public schools are transferred after 10years of continuous service in a given school. Studies in different countries show, involuntary transfers can cause stress in teachers leading to possible poor teaching performance of the transferees. However, it is admitted that transfers also help to increase the efficiency of teachers. The study presented in the paper examined how involuntary transfers impact on performance of teachers and management in public schools. The study is based on a survey conducted through a questionnaire and direct interviews in five selected schools in Colombo district representing urban and suburban areas. A random sample of teachers and the Principals of all five schools took part in the research. The study concludes that the teachers are generally not affected in personal life due to overstay transfers. The only visible impact due to housing issues can be mitigated with appropriate measures. Also overstay transfers do not have an adverse impact on the management and performance in the new school. Overall, staggered, selective and wellcoordinated overstay transfers are beneficial to schools and can be used as an opportunity to implement measures to improve academic performance and management.
\end{abstract}

Keywords: Overstay Transfers, Impact, Performance, Sri Lanka

\section{Introduction}

In many of the developing countries there is a lack of clear policy relating to teacher transfers. In many cases the policies are ad-hoc and based on factors such as personal interests, political interferences and other indirect factors rather than policies that would improve the quality of education. In certain cases, the stated policies of teacher transfer have not been developed giving due consideration to its impact on the quality of education. This study examines the effects of involuntary overstay teacher transfers on the management and academic performance in public schools involved in primary and secondary school education in Sri Lanka.

The Constitution of Sri Lanka recognizes education as a fundamental right. The United Nations Development Programme (UNDP) has identified Sri Lanka as an early achiever on 10 of the 21 indicators, including those related to the goals of universal primary education.

The present education system of Sri Lanka which was introduced by the British colonial rulers in the $19^{\text {th }}$ century is based on the British education system. The management structure of public schools is similar to the British system at the time and has gradually evolved since then. Principal and Deputy Principals act as the senior managers in the schools. Sectional Heads, Grade Coordinators, Subject Heads are at the middle management level. Many teachers become middle managers in 6 to 7 years, in a given school, depending on their experience and performance. 
Teachers employed in public schools are served with a mandatory transfer after completion of ten years of service in a given school. Such transfers are known as 'overstay transfers'. Overstay teacher transfer policy was introduced to public schools under Educational Reforms in 1998.

The objective of overstay transfers is to ensure fair distribution of talented and qualified teachers among schools and to increase the productivity of every public school. Despite of the good intentions there have been complaints that overstay transfers significantly affect the management and academic performance of both transferring and receiving schools.

Some teachers extensively involved in carrying out the strategic plans in school, are transferred before completing them. Others are transferred to schools where their area of expertise is not required. Some others who have been involved in middle management level tasks may become Assistant Teachers in the new school. It is observed that many of the teachers prefer working in one place rather than being transferred to another. All these factors will affect the performance of such teachers in their new schools while creating issues for the management of the previous school. This has led to the Department of Education regularly receiving requests from teachers and Principals of respective schools to cancel the transfers. This issue is common to many developing countries as they are challenged with significant weaknesses including the policy and implementation of recruitment and retention of personnel in the sector.

This study is conducted through a survey in five selected schools in Colombo district. A random sample of $25 \%$ of the teachers representing a cross section of each of the schools was selected for the survey. The survey was based on a questionnaire for the teachers and interviews with Principals of the respective schools. The study aims to achieve the specific objective of identifying the effects of involuntary overstay teacher transfers on the management of public schools.

\section{Research Questions}

- How does the overstay teacher transfer affect the performance of teachers in schools?

- What are the factors that hinder the good intentions of teacher transfers in relation to managing of the school?

- What are the suggestions that can be made to make transfer policy effective to improve the quality of service delivery?

- What are the alternative measures to introduce fair distribution of teachers and to improve productivity in public schools?

\section{Literature Review}

The teachers' role is very critical in the management of schools. This is clear from the definition of management. "Management" can be defined as 'the organizational process that includes strategic planning, setting objectives, managing resources, deploying the human and financial assets needed to achieve objectives, and measuring results'. Management functions are not limited to managers and supervisors. Every member of the organization has some management and reporting functions as part of their job.

\section{Is overstay transfer necessary?}

Most teachers get into the profession of teaching because of their desire to impart knowledge and gain an opportunity to offer good mentoring to the younger generation. Employment stability, opportunities for 
professional development and attractive wages are some of the key incentives for them to continue in the profession and these become the key factors contributing to job satisfaction.

Ghost (1985) argues that the overstay transfers are necessary for the efficiency of an organization. The teachers may become less effective arising from the fact that they have stayed in particular posts for a long period of time. Those transferred to new stations may perform better in those places especially if other factors, such as personal barriers, which affect their performance, are successfully tackled. This not only contributes to effective service delivery but contributes to efficiency in the education system also. In this argument, it is perceived that a teacher who changes his or her working environment quite often may perform better than someone who works in the same environment for an elongated period of time. Changes to working environment need not necessarily come from transfers. It can be introduced through other means such as changes in style of management in the school and regularly rotating the extracurricular activities within the school among the teachers.

If professional development is considered, teachers need regular opportunities to experience novel situations, gain perspective and rethink present assumptions (Harris 1980 and Howey 1981). Hollingsworth(1981), Ricken(1983) and Weller(1984) in their contributions on the emotional aspect of many transfer situations, suggest that "adequate preparation and adjustment time is a key facilitating condition in involuntary transfer situations." This can help the transferee for her/his "readiness to transfer psychologically". It is argued that with proper support, transfers can be an effective source of teacher renewal in schools. One of the ways of providing such preparatory time and adjustment may be through a well-publicized policy on transfers which lays down the incentives provided during such transfers.

\section{Factors affecting the good intentions of involuntary transfers}

Sri Lanka's teacher population is 204,908 (census in 2006) and $71 \%$ of it are females. For female teachers, working in one place rather than relocating to another becomes a preference especially due to family constraints. If such teachers are transferred his or her performance gets adversely affected in the new school at least during the initial period.

"Job transfer represents a frequent, an expensive and a potentially disruptive human resource issue" (Brett 1984). Employees appear to be increasingly reluctant to accept job transfers because of potential disruptions to their families or general quality of life (Brette and Reilly 1988). It will be very difficult for an employee to accept a transfer at a time when his or her family needs to be together. Education of the transferee's own children, health issues of family members or of themselves may not provide favourable conditions for a transfer to a new working place.

Considering that $71 \%$ of the teachers in Sri Lanka are women, the teaching profession can be identified more as a career designated for ladies. One of the main reasons for attracting ladies to teaching profession is that, the designated working hours end in the early afternoon in most schools and working duration is limited to 6 hours. Furthermore, the schools enjoy three formal vacations after each term of three months during which the teachers are hardly expected to provide any services. In the Sri Lankan culture women tend to pay more attention to the family matters than the men do. By engaging in a career like teaching, they believe they have adequate time to attend to family matters. In most cases transfer to another school in which she will have to spend more time on transportation and other matters will affect her daily routine life. This in return may not create a good environment in her new working place. Reed and Paznokas (1983) in a field study of teacher transfer and job satisfaction argued that teachers' willingness to transfer was a key factor in subsequent job satisfaction. Further, attitude towards moving significantly correlated with the willingness to relocate and predicted the subsequent decision to relocate (Brett \& Reilly, 1988).

The Educational reform report-1999, explain that by enforcing overstay transfers the Ministry of Education was attempting to improve the performance of less privileged schools in the country. One way to do so is to transfer 
well performing teachers to such schools. But considering the many factors that affect the performance of teachers shows that it is not wise to assume that prior performance in one school will always translate into equivalent success in another, specially if the transfer is not voluntary.

Slocum and Cron (1985) stated that;

"the number of transfers (mobility frequency), years of tenure (relative stability) and the attitude towards relocation (transfer) varied depending on stage of career. An employee in a very early career stage, whose primary objective is to maximize knowledge on organization and job in particular, can be expected to react differently to an involuntary transfer than one with many years of experience".

Those at an early career stage may find a transfer to a new school an opportunity to gain more knowledge and a different experience and to build new relationships which can assist his or her career development in the later stages.

Working in one place for a long time builds relationships with the students and colleagues and results in a feeling of belongingness. This facilitates the ethos of any school. Prosser \& Trig Well (1997) argue that ethos of a school is either inherited or formed by the existing members of staff, and can only be sustained in a stable environment where both teaching and non-teaching staff have a role to play. "Removal of any one party could jeopardize the entire process". Therefore, it is important to find ways to minimize such impacts during involuntary teacher transfer.

From the literature it was revealed that involuntary transfers can cause stress for the teachers, which will hinder the teaching performance in the transferees in the new schools. Furthermore, transfers are needed to increase the efficiency of the teachers.

\section{Investigation}

This section presents the methodology that was used for the study, research design, study population, sample size, sampling methods, data collection methods and instruments, validity and reliability and limitations.

The study was carried out based on the survey in five public schools in the district of Colombo, Sri Lanka. The survey included the responses from the Principals and a sample of teachers. The responding teachers from each of the schools were selected randomly and it was expected that they had the knowledge of how overstay teacher transfers would affect the management of the public schools in Sri Lanka. The five schools included both urban and suburban schools and this sample was expected to cover many of the common issues relating to the teacher transfers and how these issues have impacted the management of schools.

The five schools were selected as a purposive sample considering ease of access and type of the school.

Almost all of the teachers in these schools have experienced transfers in their career at different stages. Such transfers include those from rural areas to urban and suburban areas and vice versa.

The total sample size of the study was 105 , out of which 100 were teachers in the five different schools and the remaining 5 were Principals of respective schools. Approximately $25 \%$ out of total teacher population in each of the schools was selected randomly to form the entire sample.

\section{Sampling techniques}

Purposive sampling is a form of non-probability sampling. With this type, the sample is "hand-picked" for the research since they were the only ones of their kind. The study adopted purposive sampling method for selection of Principals in the survey. These respondents were specifically identified and picked because their technical 
knowledge on the subject and the specific nature of their involvement in the management of schools. Also simple random sampling was employed to select teachers since they were many and to avoid biasness of the responses. Random sampling was adopted by every fourth name in the Register of Attendance. The names in the register are ordered according to the time teachers joined the school.

\section{Data Collection Methods and research procedure}

This research used Questionnaire and Interview as data collection methods. The study involved primary data collected through a questionnaire and face-to-face interviews by interview guides.

The researcher's association with the teaching staff showed that the teachers would be more comfortable and reliable in expressing qualitative responses to the questions (eg. Agree, Disagree) than responding on a quantitative scale. Therefore a questionnaire, using a Likert scale, was used with the teachers. A five point scale with a neural point was chosen to allow responses from wide range of personalities including those who are indifferent to the questions. The questionnaire sought to establish how overstay transfer influences the performance of teachers in public schools and how it becomes an issue for administrative performance in schools.

The questionnaire was constructed strategically to capture all the necessary information from all categories of respondents. It was designed with simple straight forward questions which could be easily answered without any ambiguity. Few questions were also included for teachers who could afford more time for descriptive responses. The questionnaire was provided in English and Sinhalese (Language of the respondents) to ensure that the respondents choose the most comfortable language. The background information such as the age, educational qualifications and years of service was sought to establish whether there was any sign of correlation between such information and the responses.

Personal interviews with the help of an interview guide were administered to obtain responses from the Principals. The interviews were conducted in Sinhalese (and English when required) for the convenience of the participants .

The questions were framed to cover the research questions and to capture the main issues identified in the literature such as (i) level of awareness on overstay transfers which provides an indication of the respondents preparedness for such transfers (ii) how such transfers impact on the personal life of the respondents which in turn impacts on management and (iii) how respondents see overstay transfers helping performance in the present and new schools.

The researcher administered completing the questionnaire. The respondents were informed in advance and they were knowledgeable about the study. This process ensured the reliability and consistency of the responses. Also to ensure validity of instruments the researcher consulted colleagues who have conducted similar research before.

In interviews, simple language and clear instructions were used. Questions were phrased to ensure consistency in responses. Questionnaire covered common issues related to involuntary transfers. It has captured the issues identified in the literature survey and the researcher through her own experience in teaching with different responsibilities in variety of schools and the transfers she has undergone. Interview questions for the school Principals were prepared to obtain the management perspective towards overstay teacher transfers and how such transfers become an issue for the management. Interviews were conducted at the respective schools with prior appointments. Researcher noted down the responses and read back to the interviewee after completing the interview. 


\section{Limitations}

The survey sample size was limited to 5 schools and 105 respondents due to two certain limitations beyond the control of the researcher. They are (i) limited availability of human resources and time to conduct the survey (ii) limited time available for the respondents at the end of second term due to the requirement for timely completion of the lessons and end of term examinations. Further, the stated intention of the overstay transfer scheme in Sri Lanka, providing good quality teachers in schools in rural and urban poor areas is not captured in the questionnaire.

The literature relating to the subject addressed in the research is very limited and no similar attempts could be found in the context of Sri Lanka. Therefore, while the contribution of this research is pioneering in its nature, the researcher could gather very little or no lessons from the experiences and outcomes on such research in Sri Lanka in the past. However, the researcher has utilized limited work found in the literature and adopted the available work to address the issues relating to Sri Lanka to minimize her own biases towards the subject addressed.

\section{Presentation and Analysis}

Section 4 presents the findings of the study, which are presented according to the objectives. As the teacher sample was small (100), the final analysis takes the total sample as a single group without separating it by school. The response rate of the sample was $100 \%$.

\section{Background Information}

Table 1 shows the background information of the respondents in the sample survey.

Table 1 Background information of the teachers

\begin{tabular}{l|l|l}
\hline & & Percentage \\
\hline Gender & Male & $10 \%$ \\
\hline Age Group & Female & $90 \%$ \\
\hline & Less than 35 Years & $10 \%$ \\
\hline Marital Status & $36-45$ Years & $50 \%$ \\
\hline & Above 45 Years & $40 \%$ \\
\hline & Single & $5 \%$ \\
\hline Academic Qualification & Married & $85 \%$ \\
\hline & Widowed & $10 \%$ \\
\hline & Secondary School & $25 \%$ \\
\hline & Certificate & $35 \%$ \\
\hline Period of service & Diploma in Education & $25 \%$ \\
\hline & Bachelors Degree & $15 \%$ \\
\hline & $\begin{array}{l}\text { Postgraduate Diploma or } \\
\text { Masters Degree }\end{array}$ & $25 \%$ \\
\hline & Less than 15 years & $15 \%$ \\
\hline & $16-20 y e a r s$ & $40 \%$ \\
\hline & $21-25 y e a r s$ & $20 \%$ \\
\hline & More than 25years & \\
\hline & & \\
\hline
\end{tabular}


Table 1 shows that the overall sample is heavily dominated by female teachers $(90 \%)$, above the national proportion of female teachers. The age group of the sample is skewed towards the over 35 years of age (90\%). These lead to the obvious observation in the context of Sri Lanka that $95 \%$ of the respondents are either married or widowed. A proportion of $60 \%$ of the teachers have over 20 years of service. The academic qualifications are evenly spread with $75 \%$ of the teachers having qualifications beyond the secondary school certificate. The response of the teachers did not seem to correlate with the specific background information and the sample size was probably not large enough to observe any such correlation.

\section{Responses of the teachers}

The response of the teachers to the research questions were sought on a qualitative scale. It was noticed during the survey that the teachers could not really differentiate between "Agree" and "Strongly Agree". Similarly it was difficult for the respondents to distinguish between "Disagree" and "Strongly Disagree". Considering these the final presentation and analysis were confined to "Agree" combining responses of "Agree" and "Strongly Agree". "Disagree" combined the responses of "Disagree" and "Strongly Disagree". The summary of responses is in Table 2.

It was observed that $25 \%$ of the teachers are unaware of the involuntary teacher transfer scheme. Of the total $80 \%$ of the respondents were willing to accept a transfer after serving 10 years in a given school. Reed and Paznokas (1983) argued that teachers' willingness to transfer was a key factor in subsequent job satisfaction. The opinion on the impact of such involuntary transfers on the social life of the transferee and hence performance in the new school was equally split. Those who responded that such transfers impact negatively on social life thought it was more to do with difficulties relating to housing. Socio-economic profile of the students in the new school determining the negative impact was found to be minimal.

Table 2 Summary of the responses of the teachers

\begin{tabular}{l|l|l}
\hline No & Item & Proportion \\
\hline 1 & Awareness of overstay transfers & $75 \%$ \\
\hline 2 & Willing to move to a new school every 10 years & $80 \%$ \\
\hline 5 & In overstay transfers housing is an issue & $45 \%$ \\
\hline 7 & Creativity and quality of work in the new school not affected & $60 \%$ \\
\hline 8 & Teaching performance in the new school not affected & $65 \%$ \\
\hline 10 & Long stay develops a strong attachment to the school & $75 \%$ \\
\hline 11 & Long stay leads to a sense of duty to contribute more & $60 \%$ \\
\hline 12 & Long stay teachers tend to dominate over newly staff & $70 \%$ \\
\hline 13 & $\begin{array}{l}\text { overstay transfers negatively affect Implementation of the academic work plan } \\
\text { in the existing school }\end{array}$ & $40 \%$ \\
\hline
\end{tabular}

A majority of the respondents believed that their creativity and the quality of work will not be affected by any involuntary transfers but there was a significant proportion (40\%) who believed otherwise. One major reason for those who believed in negative impact was the independence they enjoy under the present management. Also respondents believe that the present student population responds positively to creative approaches to teaching and quality improvements and it may not be the case in the new school. However, this conclusion may not hold true if the new school can provide the same independent working environment and offer similar subjects for teaching. As for the quality of the student population, it is up to the teacher to employ appropriate 
approaches to teaching where his or her creativity and quality improvement efforts can still be utilised to be benefitted of the new school. It was evident from the response to the direct question on whether the teaching performance in the new school would be affected. $65 \%$ of respondents believed that it would not be so.

Most of the respondents (75\%) thought that working a longer period of time in a given school would develop a strong attachment to the school. Such attachment would lead to a development of a sense of duty to contribute to the advancement of the school. This aspect will be substantially negated by involuntary transfers. Only a few believed that such attachment is based on opportunities for career advancement.

The great majority of the respondents (70\%) indicated that a long stay in one school results in developing an attachment to the school affecting its management negatively. They tend to dominate over newly joined staff and become a barrier for the new staff to graduate into middle management. Also the management is likely to favour such long serving staff. These observations further enhance the justification for overstay transfers of certain teachers both from the school management and quality of teacher contribution point of view. However a majority of the respondents believed that the overstay transfers will impact negatively on the school management due to sudden change of the quality of staff in the context of implementing the academic work plan and various extracurricular activities. This means it is useful to provide exceptions to regular overstay transfer scheme under special circumstances if the present school is seriously affected by transfer of some teachers.

\section{Principals' Responses}

When interviewing the Principals, the researcher used pre-determined questions and obtained qualitative data. The summary of the responses are presented under each factors that were listed in the interview plan and what the Principals pointed out.

\section{Frequent change of middle managers}

In school A B and C, frequent change of middle managers has been a great issue. Assistant Principals, Grade Coordinators and Sectional Heads are selected among efficient and experienced teachers. The deputy Principals are selected through the School Principals' examination and appointed by the Ministry of Education.

The Principal of the School A, pointed out that;

"When we give positions, we cannot exclude the senior teachers even if we know that they will be transferred. We select the most deserving and some teachers can hardly be replaced. What we need in a school are efficient teachers. Those who have leadership qualities are handful and when they are taken away it will not be the same again."

Schools D and E have less than 1000 students. The deputy principals are also selected from the teaching staff itself. Hence, transferring teachers directly affects the management of these two schools.

\section{Change of teachers in charge of extracurricular work}

Schools achieve popularity and fame due to their academic performance and extracurricular activities. The most dedicated and efficient teachers are selected as teachers-in-charge for each sport or club or association. When they are transferred extracurricular activities are negatively affected.

The Principal of school C stated that;

"The teacher in charge of the swimming club was transferred two years ago. The new teachers refused to take the responsibility. The teacher-In-charge has to bring the children to a swimming pool, $1 \mathrm{~km}$ away since we don't have the facility right now. But we could not find a replacement and we had to close down the Swimming Club". 


\section{Replacements not arriving in time}

Serving in one school for more than 10 years is considered as overstay. But some teachers stay on and suddenly get a transfer and the replacements do not arrive in time. This has created a situation where long term plans are difficult to be implemented. Normally every school makes the work plan for 5 years. Those set plans are frequently affected by teacher transfers. Specially, in small schools like school E, where there are only 24 teachers, the majority of them need to be involved in management tasks. Any transfer of teachers performing these management tasks will seriously impact the management of the school.

\section{Number of teachers transferred in a year}

It is evident that the larger the teacher population, the higher number of teachers get transferred. In school A, 18 teachers have been transferred in year 2011, 16 teachers in 2012.The principal of School A pointed out;

"Within 2 years my school lose 34 teachers. It amounts to almost $30 \%$ of the staff. The number of teachers that can be transferred in a year should be limited. Otherwise it will create chaos in management of school affairs".

This response goes along with the argument (Prosser \& Trig Well, 1997) that ethos of the school significantly depend on the existing staff and can be sustained in stable environment which can be disrupted through overstay transfers. Therefore we need to find measures to minimize such disruption.

\section{Quality of replacement may not be as effective}

All schools agreed that the replacement may not be as efficient and dedicated as the transferee and the new comers need time to adjust. The attachment comes with experience in the place. Such attachment leads to teachers working more towards the development of the school.

\section{Parent-Teacher Associations and School Development Associations}

In suburban areas with fewer facilities, good quality teachers are handful. Therefore when transfers occur in such schools parents want to interfere, causing disruption to the academic work.

All Principals agreed that overstay transfers disrupt the stability of the school since it takes time for new teachers to adjust to the new environment affecting their performance. Further they had observed that the teachers lose morale to participate in the whole academic and management process of the present school when they are given involuntary transfers.

\section{Discussion}

The analysis show that the overstay transfers adversely affect the teacher performance due to (i) impact on personal life relating to housing (ii) possible absence of independence in the new school (iii) possible poor responsiveness of the students to innovative approaches to teaching in the new school and (iv) discontinuation of sense of duty to the present school developed during a long stay. This confirms the argument (Brette and Reilly 1988) that disruptions in personal life affect the performance of transferees. However the removal of the dominance of long-stay teachers over new staff through the transfer scheme positively impact teacher performance in the present school.

The management of the new school is negatively impacted by teacher performance described earlier. Similarly, the management of the present school is negatively affected when implementing the academic work plan, due to the sudden change in the composition of the well performing teaching staff. This confirms the findings of Prosser \& Trig Well (1997) that ethos of a school are largely contributed by the staff and can only be sustained 
in a stable environment. As argued by Hollingsworth(1981), Ricken(1983) and Weller(1984) the negative impact can be minimized with adequate preparation and adjustment time. Also the slow arrival of replacement and replacing middle management level teachers with less experienced ones impact teaching and the management significantly.

If the housing issues of the transferees can be addressed, a major barrier to overstay transfers in the context of transferees' personal life can be overcome. As argued by Ghost (1985) if such personal barriers can be overcome those transferred to new schools may perform better. The new school can provide the same independent working environment and offer similar subjects for teaching. Any barrier for performance due to poor quality of the student population can be overcome by employing appropriate adjustment to teaching methods where his or her creativity and quality improvement efforts can still be utilized to be benefit of the new school. By staggering and limiting the number of transfers at a given time and synchronizing the replacements well with the transfers the negative impact on the schools can be minimized.

Improving the performance of less privileged schools in the country is a key objective of overstay transfers (Educational reform report-1999). To achieve this objective the overstay transfers can still be made more effective by taking certain measures to overcome barriers as mentioned above. Further, by placing high quality new recruits in the schools where quality of teaching and management needs improvement, for a mandatory period a fair distribution of teachers can be gradually achieved.

\section{Conclusion and Recommendations}

The study attempted to address (i) Impact on overstay teacher transfer on teacher performance (ii) factors hindering the good intentions of teacher transfers in school management (iii) suggestions to make transfer policy effective to improve the quality of service delivery and (iv) alternative measures for fair distribution of teachers and to improve productivity.

\section{Conclusions}

In response to the research questions (i) and (ii), it is concluded that the teachers are unlikely to get seriously affected in personal life due to overstay transfers which is accepted as a fact in teaching profession. The only visible impact due to housing issues can be mitigated with appropriate measures. Also overstay transfers will not have a significant adverse impact on the management and academic performance in the new school. Further, the overstay transfer scheme is a useful tool to remove certain long-serving teachers dominating over school activities, negatively. This means, selective overstay transfers are beneficial to the school.

It is also concluded that the overstay teacher transfers negatively affect the teacher performance and management of the schools when such transfers are sudden and in greater numbers at a given time. Further, teacher performance can be negatively impacted if the new school is incapable of providing adequate independence and not receptive to creative approaches to teaching by new staff.

\section{Recommendations}

In response to the research questions (iii) and (iv) the following recommendations can be made.

1. Stagger overstay transfers so that a majority of those significantly contributing to management and other school activities are not transferred together.

2. Provide Exceptions to exclude transfer of teachers extensively contributing to the academic activities and management to extend their stay for some time until the impact can be made minimal. 
3. Form an independent committee under an authority beyond the level of the school to recommend such exceptions.

4. Synchronize overstay transfers to ensure that the replacements arrive within a reasonable time so that the school activities and the management are not affected adversely.

5. Train the school management to provide room for independence and creativity for the teachers.

6. Train the teachers to fast adopt to quality of new student populations

7. Providing government housing in close proximity to the school to mitigate housing issues, as presently practiced in many rural schools.

8. Encourage new comers to take over the positions of teachers-in-charge, under the guidance of experienced teachers to minimize the negative impact of overstay transfers on extracurricular activities.

9. Along with the implementation of the overstay transfers scheme, develop and implement an incentive scheme to encourage teachers to work in schools among urban poor and the rural regions to improve academic and management performance.

10. Appoint fresh graduates from the Universities and Colleges of Education to rural areas and less advantaged schools to provide an opportunity. Such an action can reduce the requirement of overstay transfers.

It is recommended that the study is extended to examine the impact of overstay transfers on academic performance of the students with emphasis on the schools accommodating most of the urban poor and rural student populations.

\section{Acknowledgement}

The author would like to acknowledge the guidance given by her supervisor Mr. Martin Brewis, School of Education, at the University of Leicester, UK and her spouse Dr. Priyantha D C Wijayatunga of Asian Development Bank, Manila, Philippines.

\section{References}

Bush,T.Bell,L. and Middlewood,D.(eds) 2010, The Principles of Educational leadership and Management $2^{\text {nd }}$ Edition,London,U.K.:Sage.

Coleman,M. and Briggs, A.R.J., 2007, Research Methods in Educational Leadership and Management $2^{\text {nd }}$ Edition,London,UK.:Sage.

Department of Education,Sri Lanka, 2006, School Census Report,Colombo,Sri Lanka:Department of Education Publications.

Ferguson,R.M.,(ed) 2002, World Education Encyclopaedia, Sri Lanka Report, 2 (3).

Fernando,Fr.M., 1991, Outline of a New Education Order for Sri Lanka, Subodhi: Institute of Integral Education.

Grissom,J. Loeb,S. and Nakashima, N.,2012, Involuntary teacher transfers and student achievement: Examining equity and efficiency ,CEPA journal paper, CENTER FOR EDUCATION POLICY ANALYSIS, Stanford University.

Hannay, L. and Chism,N.,1998, Potential of teacher transfer in fostering Professional Development.Journal of Curriculum supervision, 3(2),122-135. 
Lee,T.W. and Johnson,D.R., 1994, Reactions to job transfer by job type and career stage, Journal of Business and Psychology, 8(3).

National Institute of Education, 1998, Sri Lanka Educational Reforms report,Sri Lanka:Department of Education Publications.

Prosser, M. and Trig well, K.,1997, Relations between perceptions of the teaching environment and approaches to teaching, British Journal of Educational Psychology, 25-35.

Teacher Rules, Roles and Rights, 10/05/2012, http://www.nctq.org/tr3/issues/index.jsp?sectionId=19.

UNICEF -Education Statistics: Sri Lanka(2008),12/05/2012 www.childinfo.org/files/ROSA_Sri_Lanka.pdf 